\title{
The Impact of Insurance Status on the Development of Nonunion following Scaphoid Fracture
}

\author{
Seth D. Dodds, MD ${ }^{1}$ \\ ${ }^{1}$ Department of Orthopaedic Surgery and Rehabilitation, University \\ of Miami, Miller School of Medicine, Miami, Florida \\ ${ }^{2}$ Department of Orthopaedics and Rehabilitation, Yale School of \\ Medicine, New Haven, Connecticut \\ ${ }^{3}$ Department of Orthopaedic Surgery, Rush University Medical \\ Center, Chicago, Illinois
}

J Wrist Surg 2018;7:288-291.
Daniel D. Bohl, MD, MPH³ Raj J. Gala, MD²

\begin{abstract}
Address for correspondence Seth D. Dodds, MD, Department of Orthopaedic Surgery and Rehabilitation, University of Miami, Miller School of Medicine, Bascom Palmer Institute, 900 NW 17th Street, Suite 10A, Miami, FL 33136 (e-mail: sdodds@med.miami.edu).
\end{abstract}

\begin{abstract}
Keywords

- scaphoid fracture

- insurance

- scaphoid nonunion

Purpose Certain factors have been associated with the development of scaphoid nonunion, including delayed diagnosis, smoking, inadequate initial management, proximal location, and carpal instability. We hypothesized that insurance status would also be a risk factor for the development of scaphoid nonunion.

Methods A case-control study was performed on patients who presented to a single surgeon at a tertiary referral center during 2006 to 2015. Cases were patients presenting with nonunions, controls, and patients with acute fractures. Patients were characterized as underinsured if they lacked any type of insurance or if they were on Medicaid.

Results Patients (39 nonunions [cases] and 32 primary fractures [controls]) presenting with nonunions were more likely than controls to have had displaced fractures (72 vs. $41 \%$ ) and fractures located at the proximal aspect of the scaphoid ( $18 \mathrm{vs.} 0 \%$ ), and to be underinsured (46 vs. $19 \%$ ).

Conclusion Patients presenting with nonunions were more likely to be underinsured than patients presenting with primary fractures. This finding suggests that underinsurance is a risk factor for the development of nonunion. Assuming delay between fracture and intervention is a known risk factor for the development of nonunion, and it is likely that the association between nonunion and underinsurance is mediated through this delay. Level of Evidence Prognostic, level III, case-control study.
\end{abstract}

Appropriate initial treatment of scaphoid fractures routinely leads to reliable healing. ${ }^{1,2}$ Scaphoid nonunion, on the other hand, may occur in up to $10 \%$ of scaphoid fractures. ${ }^{3}$ When left untreated, nonunion of the scaphoid results in radiocarpal arthrosis ${ }^{4}$ and requires challenging surgical solutions. ${ }^{5}$ Several factors have been associated with nonunion development, including delayed diagnosis, proximal fracture location, degree of fracture displacement, and carpal instability. ${ }^{6}$

Many factors may play into the timing of diagnosis and treatment of scaphoid fractures. The purpose of our study was to evaluate whether or not insurance status plays a role

received

August 25, 2017

accepted after revision

February 21, 2018

published online

April 4, 2018 in how patients with scaphoid fractures are initially managed. Specifically, we hypothesized that a disproportionate percentage of underinsured individuals present with symptomatic scaphoid nonunion relative to those presenting with primary scaphoid fracture.

\section{Methods}

After obtaining Institutional Review Board approval for this study, we performed a retrospective case-control study on patients who presented to a single surgeon at a tertiary
Copyright $\odot 2018$ by Thieme Medical Publishers, Inc., 333 Seventh Avenue, New York, NY 10001, USA. Tel: +1(212) 584-4662.
DOI https://doi.org/ 10.1055/s-0038-1639509. ISSN 2163-3916. 
referral center between August 2006 and March 2015 with any of the following: new patient or consult evaluation for an (International Classification of Diseases (ICD)-9 diagnosis code 814.01 (scaphoid fracture) and/or 733.82 (fracture nonunion). In addition, using Current Procedural Terminology (CPT) code 25628 (primary scaphoid fracture repair) and CPT code 25540 (scaphoid nonunion repair), we searched for patients who had undergone surgical treatment for scaphoid fractures or scaphoid fracture nonunions. This study was performed in the United States.

After reviewing patient radiographic imaging, we defined cases as patients presenting with scaphoid nonunions and controls as patients presenting with primary scaphoid fractures. We excluded patients with other concomitant injuries such as distal radius or elbow fractures. We confirmed the appropriate diagnosis by chart review and image review, and not solely based on the ICD-9 diagnosis code or CPT code. We characterized patients as underinsured or insured. Underinsured patients had no medical insurance or Medicaid/ state-funded insurance. Insured patients had Medicare or private insurance. We collected demographic information on each patient, including age, gender, and fracture displacement ( $>1 \mathrm{~mm}$ ) based on computed tomography (CT) scan, fracture location, laterality of fracture, and insurance status by retrospectively reviewing patient medical records (both paper and electronic) and radiographs. Imaging measurements were performed by the surgeon and two senior orthopaedic residents using Synapse software (Fujifilm). Fractures were classified according to the Mayo system to determine proximal and distal pole fractures. ${ }^{7}$

Statistical analyses were conducted in Stata version 13.1 (StataCorp LP, College Station, TX). We used Pearson's chisquare test or Fischer's exact test to determine whether cases and controls differed in terms of age, gender, fracture displacement at presentation, fracture location, laterality of fracture, and insurance status. We then conducted a multivariate analysis using a backward stepwise process in which all variables associated, in bivariate analyses, with case/control status were initially included, and variables with the highest $p$-values were sequentially eliminated until all remaining variables had $p<0.20$. The level of significance was set at $p<0.05$.

\section{Results}

A total of 71 patients were identified. Of these, 32 (45\%) were primary fractures (controls) and 39 (55\%) were nonunions (cases). Nonunion patients presented on average 205 days after injury. Acute fracture patients presented on average 30 days after injury. Nonunions patients were more likely than acute fracture patients to have had fracture displacement at the time of presentation to our center ( 72 vs. $41 \%$; $p=0.015$; - Table 1). This finding makes sense, as nonunions, by nature, have a gap between the bone fragments and often a humpback deformity with displacement of the distal fragment. Nonunions were also more likely than controls to have proximal pole fractures (18 vs. $0 \%$; $p<0.001$ ) and less likely than controls to have fractures located at the distal aspect ( 0 vs. $19 \% ; p<0.001$ ).
Table 1 Characteristics of patients presenting with primary scaphoid fractures (controls) versus those presenting with scaphoid nonunions (cases)

\begin{tabular}{|c|c|c|c|}
\hline & $\begin{array}{l}\text { Primary } \\
\text { fracture } \\
\text { (controls, } \\
N=32 \text { ) }\end{array}$ & $\begin{array}{l}\text { Nonunion } \\
\text { (cases, } \\
N=39 \text { ) }\end{array}$ & $p$-Value \\
\hline $\begin{array}{l}\text { Age } \\
\text { (years } \pm \text { SD) }\end{array}$ & $29.7 \pm 19.1$ & $25.7 \pm 13.5$ & 0.302 \\
\hline Male & $25(78 \%)$ & $33(85 \%)$ & \multirow[t]{2}{*}{0.547} \\
\hline Female & 7 (22\%) & $6(15 \%)$ & \\
\hline $\begin{array}{l}\text { Nondisplaced } \\
\text { fracture }\end{array}$ & 19 (59\%) & $11(28 \%)$ & \multirow[t]{2}{*}{0.015} \\
\hline $\begin{array}{l}\text { Displaced } \\
\text { fracture }\end{array}$ & $13(41 \%)$ & $28(72 \%)$ & \\
\hline Proximal pole & $0(0 \%)$ & 7 (18\%) & \multirow[t]{3}{*}{$<0.001$} \\
\hline Mid/waist & $26(81 \%)$ & 32 (82\%) & \\
\hline Distal pole & 6 (19\%) & $0(0 \%)$ & \\
\hline Left & $13(41 \%)$ & 17 (44\%) & \multirow[t]{2}{*}{0.815} \\
\hline Right & $19(59 \%)$ & $22(56 \%)$ & \\
\hline Insured & $26(81 \%)$ & $21(54 \%)$ & \multirow[t]{2}{*}{0.023} \\
\hline Underinsured & $6(19 \%)$ & $18(46 \%)$ & \\
\hline
\end{tabular}

Abbreviation: SD, standard deviation.

Finally, nonunions were more likely than controls to be underinsured (46 vs. $19 \% ; p=0.023$ ). In the final multivariate model, the only factor that remained statistically associated with case/control status was underinsurance: nonunions were more likely than controls to be underinsured (odds ratio $=3.7 ; 95 \%$ confidence interval $=1.3$ 11; - Fig. 1). To provide a context of the percentage of underinsured in the community, the treating surgeon's breakdown, using the same definition of insured and underinsured patients in 2011 (a midpoint in the study collection), was approximately $85 \%$ insured and $15 \%$ underinsured.

We were not able to obtain complete demographic data regarding smoking, diabetes, and immunocompromised status in 12 patients in the control group and 10 patients in the nonunion group. Two patients in the control group and five patients in the nonunion group were current smokers. None of the patients in the nonunion group had diabetes; one patient was immunocompromised secondary to hepatitis $C$.

\section{Discussion}

These results confirmed our hypothesis that patients presenting with scaphoid nonunion are more likely to be underinsured than patients presenting with primary scaphoid fractures. This discovery suggests that underinsurance is a risk factor for the development of nonunion. It is important to recognize that this study implies an association rather than causation. Potential explanations for these results include disparities in time to treatment, inadequate treatment, patient noncompliance, and patient comorbidities 
Insurance Status, by Type of Presentation

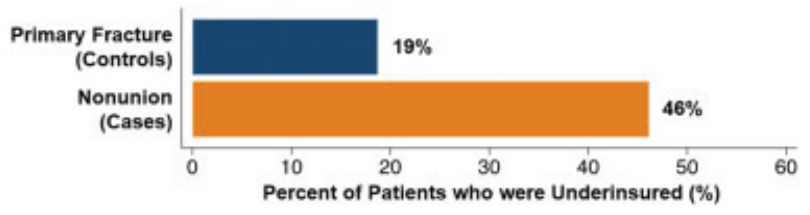

Fig. 1 This bar graph demonstrates the percentage difference of insurance status between the primary fracture group and the nonunion group. Nonunions were more likely to be underinsured than controls (odds ratio $=3.7 ; 95 \%$ confidence interval $=1.3-11$ ).

such as smoking, diabetes, and hepatitis $C$ between the two groups. Our study is limited by the fact that we were unable to obtain these specific historical data of all of our patients to create a more robust assessment of causative factors.

Due to brief and inconsistent history collections in many of our patients' charts, we are unable to offer comprehensive preoperative information on the nonunion patient cohort, specifically regarding the patients' own explanation of obstacles to treatment. However, these patients did describe two common scenarios that may have predisposed the underinsured group to nonunion: delay in diagnosis and inadequate fracture management. For example, some patients never sought treatment after their injury, assuming they sprained their wrist. Other patients did present to a medical facility for initial management of their injury. Emergency or urgent care centers would diagnose a sprain, supply a splint or brace, and suggest follow-up with a hand surgeon. Some patients may have seen a treating physician at one point in their initial management but did not complete follow-up care due to their insurance or lack thereof. A few patients described treating physicians telling them that their scaphoid fractures had healed after 4 to 6 weeks and to return as needed. Our study is also limited by the fact that we cannot honestly report these additional clinical characteristics in a scientific fashion.

In conjunction with the passage of the Affordable Care Act in 2010, there has been an increased focus on healthcare disparities for the underinsured/noninsured. Studies have demonstrated that insurance status influences orthopaedic outcomes such as timely access to specialized care ${ }^{8,9}$ and continuity of care. ${ }^{10}$ The lack of timely access by the underinsured has significant implications for scaphoid fracture care, in particular, as treatment delays alter the course of healing.

Skaggs et al demonstrated that timely access to pediatric orthopaedic care for a fictitious child with a forearm fracture was available in $100 \%$ of offices polled when the child was said to have private insurance versus in $2 \%$ of offices for a child with California Medicaid (Medi-Cal). ${ }^{11}$ Patterson et al reached similar conclusions using a fictitious adult patient, with an appointment for outpatient subspecialty care being offered within 2 weeks in $79 \%$ of offices when the patient was said to have private insurance and only $59 \%$ of offices for the patient with North Carolina Medicaid. ${ }^{12}$ Interestingly, they also found that practices in more populous areas and closer to academic medical centers were less likely to offer timely care. Given that delay between fracture and intervention is a known risk factor for the development of nonunion, we speculate that the association between nonunion and underinsurance is mediated through this delay.

This study has few strengths. A single surgeon practicing at a single tertiary referral center evaluated and treated all of the patients in this case-cohort study. We set out to answer a concise question, namely does insurance status impact scaphoid fracture healing. Our results revealed that underinsured patients had a higher incidence of scaphoid nonunion upon presentation than insured patients. With this knowledge, one then could consider underinsurance to be an indicator for the surgical management of acute scaphoid fractures, though concern for the inability to follow up could still deter surgeons from operating. Several studies have shown surgical repair of scaphoid fractures using a headless compression screw to be a reliable surgical procedure without prolonged postoperative immobilization. ${ }^{1,13,14}$ Patients who are prone to inconsistent follow-up may be better suited with a scaphoid screw (internal immobilization) rather than a cast (external immobilization) to diminish the risk of scaphoid nonunion.

Limitations of this study include its retrospective nature and narrow scope. However, the limited data on the presumed etiology of the scaphoid nonunion in the nonunion cohort group truly limit this study's effective reporting on what causes the scaphoid nonunion. It would be advantageous to conduct interviews with patients to determine the specific nature of their postinjury course to better elucidate factors other than the relationship between underinsurance and nonunion development. Most of our patients were teenagers or young adults who do not always offer consistently reliable histories; many were seen in a clinic rather than an office setting, with sparse history intake. It also is difficult to arrange follow-up assessments of this group of patients, many of whom commuted from a distance to reach our referral center. Once they were pain-free, they typically would not return for regularly scheduled office visits.

In conclusion, patients who present with a scaphoid nonunion are significantly more likely to be underinsured. Based on this finding, we recommend increased diligence when managing an underinsured patient with a scaphoid fracture. We now consider underinsurance to be reasonable indicator for the operative treatment of acute scaphoid fractures.

\section{Note}

This work was performed at the Yale School of Medicine, New Haven, Connecticut.

\section{Funding}

None.

\section{Conflict of Interest}

None. 


\section{References}

1 Bond CD, Shin AY, McBride MT, Dao KD. Percutaneous screw fixation or cast immobilization for nondisplaced scaphoid fractures. J Bone Joint Surg Am 2001;83-A(04):483-488

2 Clementson M, Jørgsholm P, Besjakov J, Thomsen N, Björkman A. Conservative treatment versus arthroscopic-assisted screw fixation of scaphoid waist fractures-a randomized trial with minimum 4-year follow-up. J Hand Surg Am 2015;40(07):1341-1348

3 Steinmann SP, Adams JE. Scaphoid fractures and nonunions: diagnosis and treatment. J Orthop Sci 2006;11(04):424-431

4 Inoue G, Sakuma M. The natural history of scaphoid non-union. Radiographical and clinical analysis in 102 cases. Arch Orthop Trauma Surg 1996;115(01):1-4

5 Slade JF III, Dodds SD. Minimally invasive management of scaphoid nonunions. Clin Orthop Relat Res 2006;445(445):108-119

6 Steinmann SP, Bishop AT, Berger RA. Use of the 1,2 intercompartmental supraretinacular artery as a vascularized pedicle bone graft for difficult scaphoid nonunion. J Hand Surg Am 2002;27 (03):391-401

7 Cooney WP, Dobyns JH, Linscheid RL. Fractures of the scaphoid: a rational approach to management. Clin Orthop Relat Res 1980; (149):90-97

8 Calfee RP, Shah CM, Canham CD, Wong AH, Gelberman RH, Goldfarb CA. The influence of insurance status on access to and utilization of a tertiary hand surgery referral center. J Bone Joint Surg Am 2012;94(23):2177-2184

9 Draeger RW, Patterson BM, Olsson EC, Schaffer A, Patterson JM. The influence of patient insurance status on access to outpatient orthopedic care for flexor tendon lacerations. J Hand Surg Am 2014;39(03):527-533

10 Wolinsky P, Kim S, Quackenbush M. Does insurance status affect continuity of care for ambulatory patients with operative fractures? J Bone Joint Surg Am 2011;93(07):680-685

11 Skaggs DL, Clemens SM, Vitale MG, Femino JD, Kay RM. Access to orthopedic care for children with medicaid versus private insurance in California. Pediatrics 2001;107(06):1405-1408

12 Patterson BM, Draeger RW, Olsson EC, Spang JT, Lin FC, Kamath GV. A regional assessment of medicaid access to outpatient orthopaedic care: the influence of population density and proximity to academic medical centers on patient access. J Bone Joint Surg Am 2014;96(18):e156

13 Slade JF III, Gutow AP, Geissler WB. Percutaneous internal fixation of scaphoid fractures via an arthroscopically assisted dorsal approach. J Bone Joint Surg Am 2002;84-A(Suppl 2):21-36

14 Slade JF, Lozano-Calderón S, Merrell G, Ring D. Arthroscopicassisted percutaneous reduction and screw fixation of displaced scaphoid fractures. J Hand Surg Eur Vol 2008;33(03): 350-354 